\title{
Agricultural residues are efficient abrasive tools for weed control
}

\author{
Manuel Perez-Ruiz ${ }^{1} \cdot$ Rocío Brenes $^{1} \cdot$ Jose M. Urbano $^{2} \cdot$ David C. Slaughter $^{3} \cdot$ Frank Forcella $^{4}$. \\ Antonio Rodríguez-Lizana ${ }^{1}$
}

Accepted: 8 March 2018 / Published online: 21 March 2018

(C) INRA and Springer-Verlag France SAS, part of Springer Nature 2018

\begin{abstract}
Non-chemical control of weeds is essential for organic farming and is a potential solution to address herbicide-resistant weeds, but too few non-chemical control methods exist. Consumers, farmers, and regulators want organic produce, new tools, and fewer xenobiotics. New weed management strategies focused on the integration of different tools, and strategies are needed to minimize dependence on broad-spectrum herbicides. Accordingly, we assessed abrasive grits from eight agricultural sources (almond shell, grape seed, maize cob, olive seed, poultry manure, sand, soybean meal, and walnut shell) as weed-abrading materials when delivered at high air pressures. Grit efficacies were determined in laboratory trials on weeds common to tomato, sugar beet, and olive: Amaranthus retroflexus L., Chenopodium murale L., and Centaurea cyanus L., respectively. Additionally, application rates and costs of residues were estimated. Control of two- to three-leaf stage weed seedlings ranged from 30 to $100 \%$. In $88 \%$ of the trials, weed control exceeded $80 \%$. Except for sand, the effectiveness of the grits was not species dependent. Significant differences in the mass flow of grits suggested that effective doses may vary up to $100 \%$ among grit materials. The residue yield ratio (percent control per gram of grit) varied among residues, ranging from 2.8 to $7.1 \% \mathrm{~g}^{-1}$. We demonstrate that the best combination of weed control, grit dose, and residue yield ratio was provided by maize cob and olive seed, with control rates of 93 and $90 \%$, respectively. This pioneering study simultaneously assessed residues from both herbaceous and woody crops as well as animal wastes and indicated that a more efficient and effective use of these resources for weed control is feasible.
\end{abstract}

Keywords Abrasion $\cdot$ Alternative weed control $\cdot$ Non-chemical application $\cdot$ Organic farming $\cdot$ Precision farming

\section{Introduction}

Agricultural systems require safe, effective, and efficient weed control operations to ensure the success of crop production (Gutjahr and Gerhards 2010). Currently, most weed control strategies in conventional agricultural production systems rely

Manuel Perez-Ruiz

manuelperez@us.es

1 Área de Ingeniería Agroforestal. Dpto. de Ingeniería Aeroespacial y Mecánica de Fluidos, Universidad de Sevilla, Ctra. Sevilla-Utrera km. 1, 41013 Seville, Spain

2 Dpto. de Ciencias Agroforestales, Universidad de Sevilla, Ctra. Sevilla-Utrera km. 1, 41013 Seville, Spain

3 Department of Biological and Agricultural Engineering, University of California, Davis, CA 65916, USA

4 North Central Soil Conservation Research Laboratory, USDA-ARS, 803 Iowa Avenue, Morris, MN 56267, USA on herbicides and/or soil tillage to control weeds (Gruber and Claupein 2009). Today's society, however, has major concerns about these agricultural practices (Gill and Garg 2014).

Postemergence herbicides are the most common form of weed control. New precision spraying systems increase application accuracy and reduce amounts of herbicide applied (Pérez-Ruiz et al. 2015). These developments greatly improve the economic and environmental outlook for herbicides. Nevertheless, herbicide use still represents an economic burden as well as concerns for the environment, human health, and evolution of resistance (Clarke et al. 2011; Curran 2016; Hull et al. 2014; Reisch et al. 2013).

Alternative technologies to herbicides exist for weeds that grow between crop rows (e.g., brush weeders, disc cultivators, rolling cultivators). A critical need remains, however, for the development of weed control technology involving the removal of weeds growing between crop plants within the crop row (i.e., intra-row weed control). In the absence of selective herbicides, removal of these weeds is still largely accomplished by hand-hoeing, even though hoeing can cost up to 
five times as much as conventional cultivation techniques (Slaughter et al. 2008).

Weed management is the most important agronomic issue in organic cropping systems according to farmer surveys (Walz 1999). Mechanical weed control is the most commonly used form of weed control in such systems, but it requires large investments in energy, labor, and time. In addition, its speed and accuracy are restricted by the skills and experience of the crew. Alternative techniques to hand-weeding have been developed for intra-row weeds (Van Evert et al. 2011), and these largely depend on soil disturbance, which impacts the release of nitrous oxide $\left(\mathrm{N}_{2} \mathrm{O}\right)$ and $\mathrm{CO}_{2}$ from the soil (Carbonell-Bojollo et al. 2012; Reicosky and Forcella 1998). Thus, the $\mathrm{C}-\mathrm{N}$ footprint left by organic agriculture may be comparable to that of conventional agriculture (Qin et al. 2010). To minimize the negative effects of tillage on soil quality and carbon sequestration, farmers are encouraged to minimize their tillage operations. Reduced and no-tillage techniques in arable cropping systems protect soil from erosion (Rodríguez-Lizana et al. 2010; Rodríguez-Lizana et al. 2017) and increase soil organic matter and $\mathrm{C}$ sequestration (RepulloRuibérriz de Torres et al. 2012). However, these techniques may augment weed infestations (Podolsky et al. 2016).

In organic cropping systems, optimum weed suppression is typically achieved when a combination of strategies (e.g., flame weeding, precision hoeing, and high-sowing rate) is deployed within the same growing season (Fontanelli et al. 2013). However, not all combinations of strategies are compatible. For example, neither flame weeding nor mechanical tillage can be used to control weeds growing through plastic mulch (Wortman 2015). Thus, continued innovation is needed to develop physical weed management strategies that are compatible with a broad range of other weeding strategies.

New developments in non-chemical intra-row weeding include flaming (Ulloa et al. 2010), co-robots (Pérez-Ruiz et al. 2014), and RTK-GNSS-based crop plant maps (Perez-Ruiz et al. 2012). However, these systems may be cost-prohibitive for many organic and small-scale farmers even though current intra-row weed control via hand-weeding also is costly for most farmers (Sivesind et al. 2009). Thus, new methods of intra-row weed control still are needed.

A new intra-row weeding method involves the use of airpropelled abrasive grit. The grits are small particles that abrade small weed seedlings within the crop row but leave crop plants unharmed. Various grits derived from agricultural residues (e.g., corn cobs, walnut shells) can be used for postemergence control of weeds (Forcella 2009), including selective control within rows of agronomic and horticultural crops (Erazo-Barradas et al. 2017; Forcella 2012, 2013; Wortman $2014,2015)$. Some organically approved fertilizers also can work effectively as weed-abrading grits (Wortman 2014, 2015; Forcella et al. 2011).
Prior studies with abrasive grits focused on (i) the use of a very small range of agricultural residues (Wortman 2015), (ii) specific weeds, (iii) grit delivery patterns (Forcella 2009), or (iv) phenological stages for grit application (Forcella 2013). Many unanswered questions remain for this new technique.

In this study, effects on weeds were examined for abrasive grits derived from both herbaceous and woody crops as well as animal wastes. The weed species were common and representative of three types of crops (Fig. 1). The costs of the materials were also estimated to determine the potential for their practical implementation. Eight residues were studied, including those from common crops, to evaluate the potential of this technique to make use of widely available agricultural residues and waste materials.

The two specific objectives of the current study were as follows: (i) test laboratory applications of eight abrasive grits (almond shell, grape pomace, maize cob, olive seed, poultry manure, sand, soybean seedmeal, and walnut shell) on seedlings of three weeds species (Amaranthus retroflexus L., Chenopodium murale L., and Centaurea cyanus L.) that are common throughout southern Europe in transplanted vegetable crops (tomato), agronomic crops (sugar beet), and orchard crops (olive), respectively; and (ii) determine the likely application rates and costs for abrasive grits in these three crops.

\section{Materials and methods}

\subsection{Abrasive grits}

Grits included those derived from woody crops (olive seed, almond shell, walnut shell, and grape pomace), arable crops (maize cob and soybean meal), animals (poultry manure), and sand. Average particle sizes (mm) for these grits were 1.2, 0.8, $0.8,1.5,0.7,1.5,1.7$, and 0.4 , respectively. The maize cob, pelletized poultry manure, soybean seed meal, and walnut shell were from commercial sources; the remainder was processed in our laboratory.

\subsection{Condensed-air machinery}

A small, portable laboratory grit applicator that was similar to a sand blaster in terms of functionality was designed to facilitate grit application by adjusting air pressure, flow, and direction. The system consists of a pistol-type gun and grit reservoir (Model 9 1, JOMAR S.L., Seville, Spain), 500 L air compressor (Model B5900B/500 FT 5,5 15B E, ABAC/American IMC, Inc., Rock Hill, South Dakota, USA) and a specific nozzle connected by high-pressure rubber hoses. One hose is used for grit intake and draws from a reservoir tank of grit; the second hose is used for air intake and is coupled to the air compressor. Once the nozzle is open, compressed air passes over the top of the grit hose and through the nozzle, thereby 

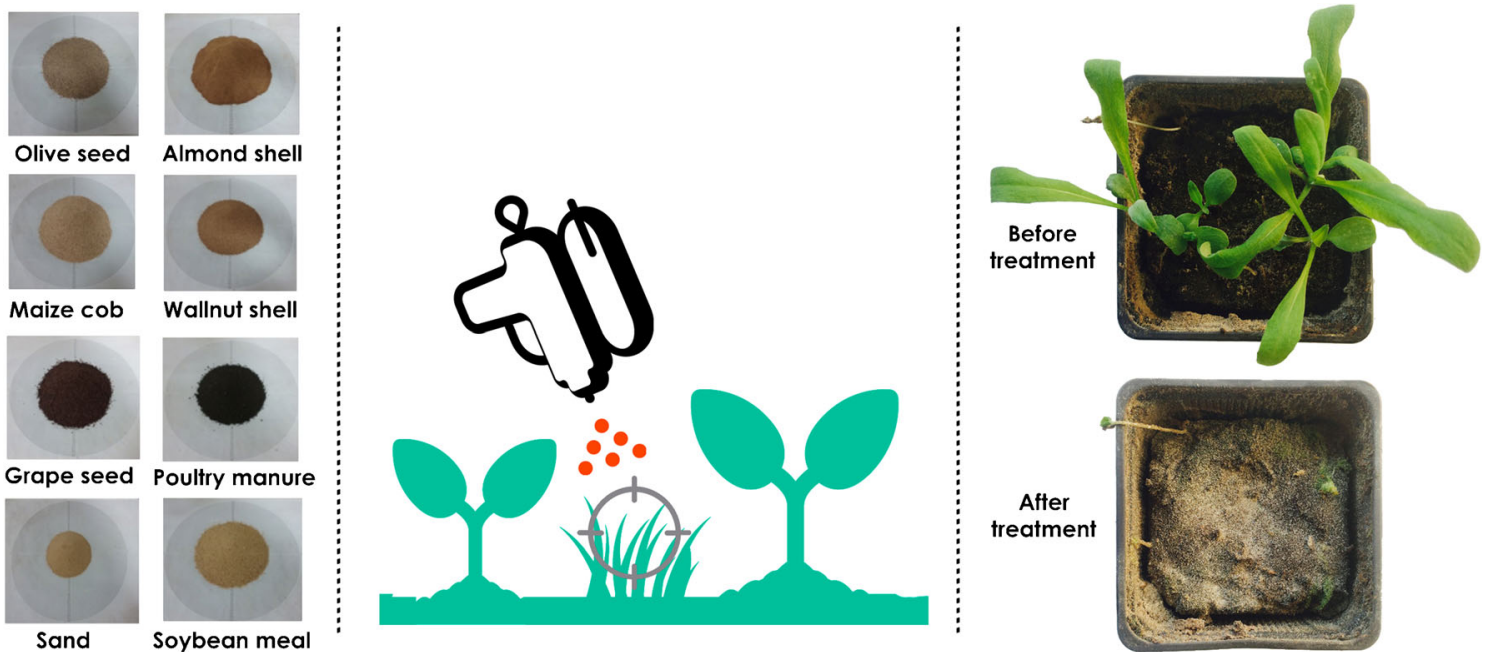

Fig. 1 Left: images of the agricultural wastes. Center: illustration of a treatment on small weeds. Right: before and after examples of the effect of the grit on seedlings of the weed, C. cyanus

creating a vacuum that draws grit from the tank through the grit hose and out of the nozzle. This system allows for a wide range of easily repeatable laboratory tests (see sections 2.2 and 2.3 ). The system required a uniform grit particle size to avoid clogging; thus, all grits were processed by using a mill (Redume S.A., Alcalá de Guadaíra, Spain) before application. Air pressure $(\mathrm{kPa})$ and flow $\left(\mathrm{kgh}^{-1}\right)$ through the nozzle were monitored.

\subsection{Determination of the success rate of eliminating weeds}

Seeds of three weed species were sown in $70 \times 70 \times 80 \mathrm{~mm}$ pots filled with $0.24 \mathrm{~L}$ of a fine-grained potting substrate $(0.1 \mathrm{~mm} \leq \varnothing \leq 10 \mathrm{~mm})$ and grown in a growth chamber with alternating night/day cycles of $9 / 16 \mathrm{~h}, 23 / 25^{\circ} \mathrm{C}$, and $45 / 60 \%$ relative humidity. Photosynthetically active radiation was $22 \mathrm{~W} \mathrm{~m}^{-2}$. When the seedlings were at the two- to three-leaf stages of growth, they were exposed to grit propelled with air at $800 \mathrm{kPa}$ for $4 \mathrm{~s}$. For each type of residue, ten seedlings of each species were tested. Damage and regrowth were assessed visually at 14 days after exposure to grit.

To predict the success rate, the probability $(P)$ of removing a weed by a specific residue, multiple binary logistic regression with categorical independent variables, was used [Eq. 1].

$\operatorname{logit}(P)=\ln \frac{P}{1-P}=\alpha+\sum_{i=1}^{8} \beta_{i} \cdot Z_{i}+\sum_{j=1}^{2} \lambda_{j} \cdot Z_{j}^{\prime}+\sum_{j=1}^{2} \sum_{i=1}^{8} \theta_{i j} \cdot Z_{i} \cdot Z_{j}^{\prime}$

where logit $(P)$ is the logit function, which is defined as the natural logarithm of the ratio between the probability of success $(P)$ and failure (1-P) for a given species (represented in the model by $Z_{j}^{*}$, with three levels) and a particular type of residue (represented by $Z_{\mathrm{i}}$, with nine levels: eight residues plus a control treatment). For modeling, in addition to the indicator variables $Z_{\mathrm{j}}^{\prime}$ and $Z_{\mathrm{i}}$, their interactions were used to explain possible variations in the elimination of a species for the same residue.

The covariates were considered individually significant in the model if the $p$ value of the estimate was less than 0.01 . The $G^{2}$ (deviance) statistic was used to test the null hypothesis of the fit of the model to the sample and was distributed according to $X^{2}{ }_{n-(k+1)}$, where $n$ is the number of observations and $k$ is the number of covariates in the model.

For the evaluation of the modeling capacity of $P$ from the logistic regression model, a comparison was made between the observed and predicted frequencies for each group. To measure the goodness of fit of the model, the percentage of events correctly predicted was made by assigning a value of one to the estimated probabilities greater than 0.5 and a value of 0 was assigned to the lower probabilities (Wooldridge 2013). To compare the different residues, the relative success rate (TER) was utilized [Eq. 2]. TER is calculated as the ratio of the odds of success of a particular residue against a standard or reference residue, which may be more common in the area. Because olive is the most common woody crop in Spain (2.5 Mha) (Ministry of Agriculture, Food and Environment 2015), its seed grit was chosen as the reference residue, as expressed in Eq. [2].

TER $_{\text {residue } i}=\frac{P_{\text {residue } i}}{P_{\text {crushed olive }}}$

where $P_{\text {residuei }}$ and $P_{\text {crushed olive }}$ refer to the success rate of weed elimination for the residue $i$ and for olive seed grit, respectively. In those cases where the rate of removal of the model also depends on the species, the TER is specified for each of them. Statistical models were generated with $\mathrm{R}$. 


\subsection{Residue flow comparison}

For this experiment, all the residues were propelled by air for a period of $4 \mathrm{~s}$ at $800 \mathrm{kPa}$. For each test, the amount of grit applied was collected and weighed. Ten replications were made per residue. Univariate analysis of variance (ANOVA) was used to test the equality of residue mass collected as a function of the type of residue. This factor had eight levels, corresponding to the eight types of residue used in this research. Normality was tested using the Shapiro-Wilk test, and the homogeneity of variance was assessed using the Levene test (Levene 1960). None of the data transformations attempted achieved complete fulfillment of ANOVA criteria. Thus, in view of the absence of normality (grape seed) and variance homogeneity, robust generalizations of Welch's test and Box's test were employed. The null hypothesis compared the equality of 0.2-trimmed means. Differences between means in the model were compared based on the YuenWelch test (Yuen 1974).

To determine the degree of association between the residue mass collected and weed elimination rate (see Section 2.3), the Spearman non-parametric correlation coefficient $r h o$ was used [Eq. 3]. This term measures the correspondence of the ranks assigned to the observations for each variable and is calculated as follows:

$r_{s}=1-\frac{6 \sum d_{i}^{2}}{n\left(n^{2}-1\right)}$

where $n$ is the number of observations, and $d_{i}$ is the difference in ranks for the $i^{\text {th }}$ pair. The value $r_{s}=1$ corresponds to the identification of the ranks of both variables, i.e., to a growing monotonic association between the variables. The closer to 1 , the higher the degree of positive association.

The residue yield ratio [Eq. 4] was calculated. This value is the quotient between the weed elimination rate and the collected residue amount. This ratio provides a global value of the potential of every residue since the higher this ratio, the more efficient a residue is for killing weeds. A residue would be classified as optimal if it simultaneously has a high-residue yield ratio and is common in the area.

Residue yield ration $=\frac{\text { Killing } \operatorname{rate}(\%)}{\text { Residue } \operatorname{amount}(\mathrm{g})}$

For the aforementioned statistical analysis, the $R$ statistical software was used (R Core Team 2015).

\subsection{Economic feasibility of using grit}

The following assumptions were established to determine the cost of different residues and to rank their utility. One field pass traveling approximately $1.6 \mathrm{~km} \mathrm{~h}^{-1}$ with grit applications made with one nozzle aimed at one side of one crop row. The average emission rate of grit $\left(\mathrm{g} \mathrm{s}^{-1}\right)$ from a single nozzle was known (section 2.4). Three real-farm situations, with a range of row spacings were simulated for study of the potential economic cost of each grit: (a) a beet field with row spacing of $0.5 \mathrm{~m}$, (b) a tomato field with row spacing of $1.5 \mathrm{~m}$, and (c) an olive orchard with row spacing of $6 \mathrm{~m}$. The price of maize cob grit and poultry manure was assumed to be 1.5 and $1.4 € \mathrm{~kg}^{-1}$, respectively.

\section{Results and discussion}

\subsection{Determination of the success rate of eliminating weeds}

Frequencies of success for eliminating weeds by the differing grits are presented in Table 1. Percentages range from 30 to $100 \%$. Effectiveness was less than $80 \%$ in only three of 24 cases in which abrasive grit was applied (Table 1). The lowest success rate occurred for sand in C. murale (30\%) compared with a $90 \%$ success rate archived for the other species with the same residue.

The resulting estimates of the parameters of the global model, which initially comprised all treatments and species [Eq. 1], were only significant ( $p$ values $<10^{-4}$ ) in covariates $Z_{1}$, which represent the residues used in the trials. Null hypothesis model adequacy was accepted according to the significance of $G^{2}(p=0.9)$. The $p$ values of the coefficients of covariates $Z_{1}$ indicate significant differences among them. However, the differences were occasionally not relevant at the practical level, as evidenced by the frequencies in Table 1 . The only interaction that was significant was that of the behavior of $C$. murale with sand $(p=0.0027)$.

The fact that significant results had only the coefficients associated with the types of residue (Table 1) indicates that the susceptibility of each plant to weeding with abrasive grit is constant and independent of the species on which the application was performed. This finding is interesting, because it suggests uniform behavior for each residue (Table 1) with the exception of sand, as reflected in the significance of the coefficient associated with covariate $Z_{1} Z_{2}^{\prime}(p=0.0027)$.

Errors in success rates were generally small and rarely greater than 0.15 (absolute value) (Table 1); thus, the model showed good predictive ability. Errors were somewhat greater in cases in which some sample variability occurred between species, e.g., almond shell and grape seed.

Of the 246 weed seedlings that were subjected to abrasion by grit, the statistical model correctly classified 216 ( $88 \%$ of all observations). With all coefficient estimates of $\beta$ being positive, a higher value indicates a higher probability of success of the residue. Thus, walnut shell, maize cob, and olive seed grit were the most efficient, with $\beta$ equal to 5.85, 5.12, and 4.92 , respectively, which correspond to proportionate 
Table 1 Comparison among frequencies of weed injury models and tests

\begin{tabular}{|c|c|c|c|c|c|c|}
\hline Treatment & Weed & $\begin{array}{l}\text { Fitted } \\
\text { probability }\end{array}$ & $\begin{array}{l}\text { Trial } \\
\text { probability }\end{array}$ & Error & $\begin{array}{l}\text { Mean } \\
\text { (treatment) }\end{array}$ & $\begin{array}{l}\text { Relative } \\
\text { success rate }\end{array}$ \\
\hline \multirow[t]{3}{*}{ Sand } & Amaranthus spp & 0.90 & 0.90 & 0.00 & & 0.98 \\
\hline & Chenopodium spp & 0.30 & 0.30 & 0.00 & & 0.33 \\
\hline & Centaurea spp & 0.90 & 0.90 & 0.00 & 0.70 & 0.98 \\
\hline \multirow[t]{3}{*}{ Olive seed } & Amaranthus spp & 0.92 & 0.90 & 0.02 & & \\
\hline & Chenopodium spp & 0.92 & 1.00 & -0.08 & & \\
\hline & Centaurea spp & 0.92 & 0.80 & 0.12 & 0.90 & 1 \\
\hline \multirow[t]{3}{*}{ Walnut shell } & Amaranthus spp & 0.97 & 1.00 & -0.03 & & \\
\hline & Chenopodium spp & 0.97 & 0.90 & 0.07 & & \\
\hline & Centaurea spp & 0.97 & 1.00 & -0.03 & 0.97 & 1.05 \\
\hline \multirow[t]{3}{*}{ Maize cob } & Amaranthus spp & 0.93 & 1.00 & -0.07 & & \\
\hline & Chenopodium spp & 0.93 & 0.90 & 0.03 & & \\
\hline & Centaurea spp & 0.93 & 0.90 & 0.03 & 0.93 & 1.01 \\
\hline \multirow[t]{3}{*}{ Poultry manure } & Amaranthus spp & 0.90 & 1.00 & -0.10 & & \\
\hline & Chenopodium spp & 0.90 & 0.80 & 0.10 & & \\
\hline & Centaurea spp & 0.90 & 0.90 & 0.00 & 0.90 & 0.98 \\
\hline \multirow[t]{3}{*}{ Soybean meal } & Amaranthus spp & 0.84 & 0.80 & 0.04 & & \\
\hline & Chenopodium spp & 0.84 & 0.80 & 0.04 & & \\
\hline & Centaurea spp & 0.84 & 0.90 & -0.06 & 0.83 & 0.91 \\
\hline \multirow[t]{3}{*}{ Almond shell } & Amaranthus spp & 0.87 & 0.90 & -0.03 & & \\
\hline & Chenopodium spp & 0.87 & 1.00 & -0.13 & & \\
\hline & Centaurea spp & 0.87 & 0.70 & 0.17 & 0.87 & 0.95 \\
\hline \multirow[t]{3}{*}{ Grape seed } & Amaranthus spp & 0.73 & 0.90 & -0.17 & & \\
\hline & Chenopodium spp & 0.73 & 0.50 & 0.23 & & \\
\hline & Centaurea spp & 0.73 & 0.80 & -0.07 & 0.73 & 0.79 \\
\hline \multirow[t]{3}{*}{ Control } & Amaranthus spp & 0.08 & 0.00 & 0.08 & & \\
\hline & Chenopodium spp & 0.08 & 0.00 & 0.08 & & \\
\hline & Centaurea spp & 0.08 & 0.22 & -0.15 & 0.08 & 0.09 \\
\hline
\end{tabular}

control values greater than 0.9 as shown in Table 1. Walnut shell grit controlled almost all of the treated weeds ( 29 out of 30) and had a TER of 1.05 compared to the standard residue (olive).

\subsection{Residue flow comparison}

Regarding the residue flow in the experiment, significant differences were obtained $\left(p<10^{-5}\right.$ in Welch's test and Box's test), as shown in Fig. 2. Sand had the greatest amount collected in the test and differed from the other grits. A wide variability among residue masses was observed in this test; the greatest residue amount was approximately twice that of the second greatest, which implies a much higher dose applied in the field in the case of sand at an equal application pressure. However, the Spearman correlation between the rank by mass applied of grit type vs. weed elimination ranking was not significantly different from zero $\left(r_{\mathrm{s}}=0.03, p=0.95, n=8\right)$, suggesting that a ranking of grit types by mass applied is not a useful indicator of weed removal efficacy.

The residue yield ratio [Eq. 4] of maize cob was unusually high at $7.1 \% \mathrm{~g}^{-1}$ (Fig. 2). In comparison, sand seemed to be the least promising of the analyzed materials, at least according to its low-residue yield ratio $\left(2.9 \% \mathrm{~g}^{-1}\right)$, which was caused by a high mass of propelled residue and a simultaneous lowweed elimination rate. The remaining materials had similar values, ranging between 4.8 and $5.6 \% \mathrm{~g}^{-1}$ (Fig. 2).

These figures raise questions at a practical level. If we consider that higher doses do not correspond to higher rates of weed removal, then olive seed and maize cob grits should be selected for use. In the first case, olive is a crop residue with easy accessibility in the region (Ministry of Agriculture, Food and Environment 2015) and exhibits a reasonable yield ratio at $5.2 \% \mathrm{~g}^{-1}$. In contrast, maize cob grit exhibited an appreciable reduction in dosage compared with olive seed grit and shows a TER equal to 1.01. In addition, the second case had the best residue yield ratio, with higher performance than the 


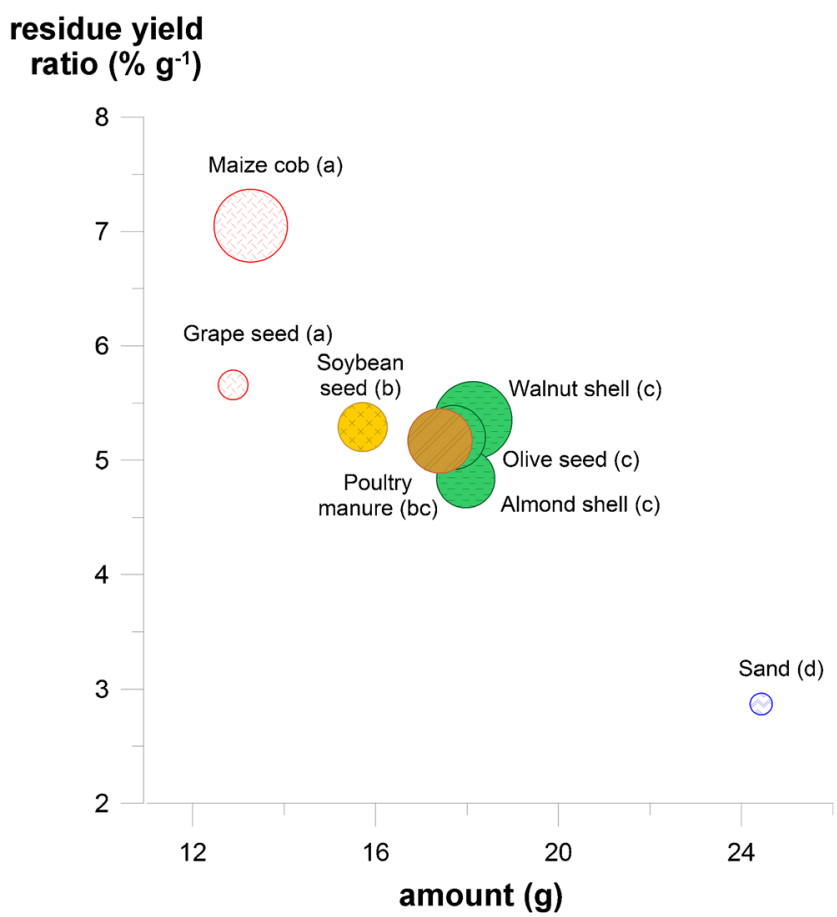

Fig. 2 Relationship between the residue yield ratio and the amount of grit measured in the dosage experiment. The diameter of the circles are directly proportional to the killing rate of each residue. The larger the diameter and the smaller the amount, the better the residue is for agricultural use. Residues with different letters exhibit significantly different amounts $(p<0.05)$

remaining grit types. Thus, olive seeds and maize cobs appear to be the most promising agents based on these tests and the weed elimination rates of equal or superior to $90 \%$ (Table 1).

\subsection{Grit application rate and potential material cost}

Figure 3 presents the amount of grit that would have been applied per treatment on a hectare basis given the assumptions of section 2.5 .
For tomato and sugar beet, the sand was the grit type with the highest consumption, which was $80 \%$ greater than that of maize cob grit. This consumption was similar to the rates determined by Forcella (2012) at $253 \mathrm{~kg} \mathrm{ha}^{-1}$ and Wortman (2014) at $206 \mathrm{~kg} \mathrm{ha}^{-1}$. This rate of residue use may be feasible in crops such as tomatoes and beets, especially when compared with manual weeding, where between 200 and 400 man-hours ha ${ }^{1}$ are needed (González 2006).

The application of agricultural residues to irrigated olive groves may be of interest for two reasons. As indicated by Pastor (2005), there is a very small area where irrigation water is applied (the drip strip), which is almost always under trees, with an area equivalent to 3 to $5 \%$ of the orchard. Herbicides typically are used in these dampened strips, where they may be degraded rapidly and mobilized easily. Weeds may germinate in a staggered manner in these strips, and many species now are tolerant to commonly used herbicides, which makes management of the strip difficult (Pastor 2005). Thus, the application of gritty residues may be of potential interest in both conventional and organic olive orchards (i.e., applying grit in the strip along the drip lines) due to the limited land area requiring treatment, reducing the amount of residue required.

The costs of all tested grits are not well established, especially if purchased in bulk. Maize cob grit is sold in 20-kg bags for approximately $30 €$ or $1.5 € \mathrm{~kg}^{-1}$. Poultry manure sells for $1.4 € \mathrm{~kg}^{-1}$. Thus, poultry grit and maize cob grit have a similar financial cost. Assuming grits (excluding sand) were of equal cost, then a single abrasive grit treatment has an estimated material cost of 321 to $441 € \mathrm{ha}^{-1}$ for beet, 107 to $147 € \mathrm{ha}^{-1}$ for tomato, and 27 to $36 € \mathrm{ha}^{-1}$ for olive. (These estimates represent "materials costs" only, as equipment and application costs for this new technique are unknown at this time.) Two grit applications are needed for season-long weed control in maize (Erazo-Barradas et al. 2017) and tomato (Wortman 2015). Despite the many unknowns, these monetary values are low in comparison to hand weeding. Even at a
Fig. 3 Average consumption of each abrasive grit in one field pass traveling approximately $1.6 \mathrm{~km} \mathrm{~h}^{-1}$ in three cropping scenarios

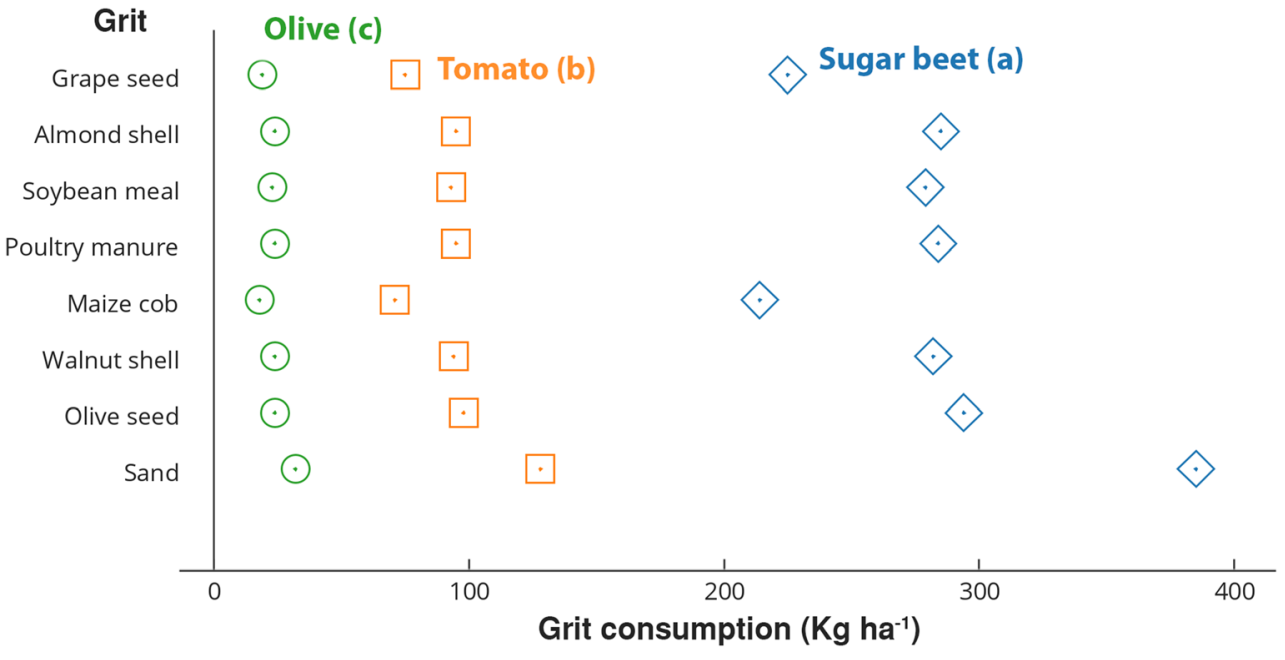


low labor cost of $10 € \mathrm{~h}^{-1}$, hand weeding could be valued at thousands of euros per hectare. Thus, the results of the study demonstrate the potential use of agricultural residues in crops to control weeds in terms of their materials cost per hectare.

Possibilities exist for reducing costs of grit-based weed control. For example, on-farm collection and milling of grit would lower its costs (Forcella 2012), as would the use of sensors for detecting weeds to apply grit only where necessary. Utilizing GNSS-RTK crop maps to determine the geospatial position of the grit applicator with respect to each mapped crop plant in the field could substantially reduce the applied area (Pérez-Ruiz et al. 2012). In addition, if organicapproved gritty fertilizers, such as the poultry manure $(8 \%$ nitrogen) we tested, could be applied as abrasive grits to control weeds, then this would help provide weed control and with added benefits for soil fertility.

\section{Conclusion}

Weed control relies heavily on cropping system methods coupled with chemical and mechanical techniques. The need for alternative weed control management practices has been constantly increasing, especially in organic farming systems. This need has arisen due to several environmental, sustainability, and health issues that have emerged within the farming community and the public. One new alternative method of weed control is the use of abrasive grit. Based on our results, we conclude the following:

- Agricultural materials usually considered as wastes or residues can be used successfully for the non-chemical control of weeds, an issue of special interest in organic farming.

- For the three weed species studied, the susceptibility of each weed to control with specific abrasive grits is constant and independent of the species on which the application was made. This initial finding is important because it suggests uniform behavior by each residue, at least for the three broadleaf weeds examined (Amaranthus, Centaurea, and Chenopodium)

- Large dose variation, above $100 \%$, among residues when applied at a constant pressure were observed. However, these variations were not reflected in corresponding changes in the percentage of weed control for the weed species studied.

- Walnut shell, poultry manure, maize cob, and olive seed grit were the most efficient grits, with control values greater than or equal to $0.9(90 \%)$ in all cases. When the elimination percentages of the dose are considered, the two most promising residues were maize cob and olive seed, with maize being highly efficient as reflected in its highresidue yield ratio.
- The costs of the applied residues, according to market prices (where available), likely would be acceptable to organic farmers, especially in comparison to hand weeding.

Overall, walnut shell was the residue with the greatest weed control effect. This residue killed almost all of the treated weeds ( 29 pots out 30 ) and had a TER of 1.05 compared to the standard residue. Thus, considering that these preliminary tests were conducted at weed growth stages recommended for applications (two- to three-leaf seedlings) (Forcella 2009), walnut shell is the material most effective at removing weeds via air-propelled mechanical impact of grit. However, olive seed and maize cob grits also appear promising. Examining a greater number of weed species and types of grit and understanding the properties of grits (such as surface roughness and density) that promote better control would enable an even greater understanding of the best ways to improve this new weed control technology.

Acknowledgements The research was supported in part by the Spanish Ministry of Economic and Competence (Project: AGL2013-46343-R) and the Regional Government of Andalucía (Project: P12-AGR-1227).

\section{References}

Carbonell-Bojollo RM, Repullo-Ruibérriz de Torres MA, RodríguezLizana A, Ordóñez-Fernández R (2012) Influence of soil and climate conditions on $\mathrm{CO}_{2}$ emissions from agricultural soils. Water Air Soil Pollut 223:3425-3435. https://doi.org/10.1007/s11270-012$1121-9$

Clarke JH, Wynn SC, Twining SE (2011) Impact of changing pesticide availability. Aspect Appl Biol 10:263-267

Curran WE (2016) Persistence of herbicides in soil. Crops and Soils Magazine. American Society of Agronomy, Madison, pp 16-21. https://doi.org/10.2134/cs2016-49-0504

Erazo-Barradas M, Forcella F, Humburg D, Clay SA (2017) Propelled abrasive grit for weed control in organic silage corn. Renewable Agric Food Syst 1-8. https://doi.org/10.1017/S174217051700031X

Fontanelli M, Raffaelli M, Martelloni L, Frasconi C, Peruzzi A (2013) The influence of non-living mulch, mechanical and thermal treatments on weed population and yield of rainfed fresh-market tomato (Solanum lycopersicum L.) Span J Agric Res 11:593-602. https:// doi.org/10.5424/sjar/2013113-3394

Forcella F (2009) Potential use of abrasive air-propelled agricultural residues for weed control. Weed Res 49:341-345. https://doi.org/10. $1111 / j .1365-3180.2009 .00711 . x$

Forcella F (2012) Air-propelled abrasive grit for postemergence in-row weed control in field corn. Weed Technol 26:161-164. https://doi. org/10.1614/WT-D-11-00051.1

Forcella F (2013) Soybean seedlings tolerate abrasion from air-propelled grit. Weed Technol 27:631-635. https://doi.org/10.1614/WT-D-1200192.1

Forcella F, James T, Rahman A (2011) Post-emergence weed control through abrasion with an approved organic fertilizer. Renewable Agric Food Syst 26(1):31-37. https://doi.org/10.1017/ S1742170510000438 
Gill HK, Garg H (2014) Pesticide: environmental impacts and management strategies. In: Solenski S, Larramenday ML (eds) Pesticidestoxic effects. Intech. Rijeka, Croatia, pp 187-230. https://doi.org/10. $5772 / 57399$

González R (2006) Métodos para el control de malas hierbas. (1) culturales. Instituto de Ciencias Agrarias (ICA). Centro de Ciencias Medioambientales (CCMA) Consejo Superior de Investigaciones Científicas (CSICI). Hoja divulgativa Núm. 2119

Gruber S, Claupein W (2009) Effect of tillage intensity on weed infestation in organic farming. Soil Tillage Res 105:104-111. https://doi. org/10.1016/j.still.2009.06.001

Gutjahr C, Gerhards R (2010) Decision rules for site-specific weed management. In E.-C. Oerke et al. (ed) Precision Crop Protection - the Challenge and the Use of Heterogeneity. Springer Science. pp 223239. https://doi.org/10.1007/978-90-481-9277-9 14

Hull R, Tatnell LV, Cook SK, Beffa R, Moss SR (2014) Current status of herbicide-resistant weeds in the UK. Asp Appl Biol 127:261-272

Levene H (1960) Robust tests for equality of variances. In: Ingram Olkin; Harold Hotelling; et al. contributions to probability and statistics: essays in honor of Harold Hotelling. Stanford University Press, pp 278-292

Ministerio de Agricultura, Alimentación y Medio Ambiente (2015) Encuesta sobre superficies y rendimientos de cultivos. Resultados nacionales y autonómicos. http://magrama.gob.es/es/estadistica/ temas/estadisticas-agrarias/agricultura/esyrce/. Accessed 05 Dec 2016

Pastor M (2005) Mantenimiento del suelo en olivar de regadío: manejo del suelo y los herbicidas. In: Pastor M (ed) Cultivo del olivo con riego localizado. Junta de Andalucía \& Mundi-Prensa, Madrid, pp 589-624

Perez-Ruiz M, Slaughter DC, Gliever C, Upadyaya S (2012) Tractorbased real-time kinematic-global positioning system (RTK-GPS) guidance system for geospatial mapping of row crop transplant. Biosyst Eng 111:64-71. https://doi.org/10.1016/j.biosystemseng. 2011.10.009

Pérez-Ruiz M, Slaughter DC, Fathallah FA, Gliever CJ, Miller BJ (2014) Co-robotic intra-row weed control system. Biosyst Eng 126:45-55. https://doi.org/10.1016/j.biosystemseng.2014.07.009

Pérez-Ruiz M, Gonzalez-de-Santos P, Ribeiro A, Fernandez-Quintanilla C, Peruzzi A, Vieri M, Tomic S, Agüera J (2015) Highlights and preliminary results for autonomous crop protection. Comput Electron Agric 110:150-161. https://doi.org/10.1016/j.compag. 2014.11.010

Podolsky K, Blackshaw RE, Entz MH (2016) A comparison of reduced tillage implements for organic wheat production in western Canada. Agron J 108:2003-2014. https://doi.org/10.2134/agronj2016.01. 0032

Qin J, Hu F, Li D, Li H, Lu J, Yu R (2010) The effect of mulching, tillage and rotation on yield in non-flooded compared with flooded Rice production. J Agron Crop Sci 196:397-406. https://doi.org/10.1111/ j.1439-037X.2010.00430.x

R Core Team (2015) R: a language and environment for statistical comput- ing. R Foundation for Statistical Computing, Vienna, Austria

Reicosky DC, Forcella F (1998) Cover crop and soil quality interactions in agroecosystems. J Soil Water Conserv 53:224-229

Reisch L, Eberle U, Lorek S (2013) Sustainable food consumption: an overview of contemporary issues and policies. Sustain: Sci Pract Policy 92:7-25

Repullo-Ruibérriz de Torres MA, Carbonell-Bojollo R, Alcántara-Braña C, Rodríguez-Lizana A, Ordóñez-Fernández R (2012) Carbon sequestration potential of residues of different types of cover crops in olive groves under mediterranean climate. Spanish J Agric Res 10: 649-661. https://doi.org/10.5424/sjar/2012103-562-11

Rodríguez-Lizana A, Carbonell R, González P, Ordóñez R (2010) N, P and $\mathrm{K}$ released by the field decomposition of residues of a peawheat-sunflower rotation. Nutr Cycl Agroecosyst 87:199-208. https://doi.org/10.1007/s10705-009-9328-x

Rodríguez-Lizana A, Pereira MJ, Ribeiro MC, Soares A, Márquez-García F, Ramos A, Gil-Ribes JA (2017) Assessing soil protection uncertainty through stochastic simulations. Land Degrad Dev 28:20862097. https://doi.org/10.1002/ldr.2734

Sivesind EC, Leblanc ML, Cloutier DC, Seguin P, Stewart KA (2009) Weed response to flame weeding at different developmental stages. Weed Technol 23:438-443. https://doi.org/10.1614/WT-08-155.1

Slaughter DC, Giles DK, Downey D (2008) Autonomous robotic weed control systems: a review. Comput Electron Agric 61:63-78. https:// doi.org/10.1016/j.compag.2007.05.008

Ulloa SM, Datta A, Knezevic SZ (2010) Tolerance of selected weed species to broadcast flaming at different growth stages. Crop Prot 29:1381-1388. https://doi.org/10.1016/j.cropro.2010.04.009

Van Evert FK, Samson J, Polder G, Vijn M, Van Dooren H, Lamaker A, Der Heijden GWAM V, Van der Zalm T, Lotz LA (2011) A robot to detect and control broad-leaved dock (Rumex obtusifolius L.) in grassland. J Field Robot 28:264-277. https://doi.org/10.1002/rob. 20377

Walz E (1999) Third biennial national organic farmer's survey. Organic Farming Research Foundation, Santa Cruz

Wooldridge JM (2013) Introductory econometrics. A modern approach, 5 th edn. South Western Cengage Learning, United States

Wortman SE (2014) Integrating weed and vegetable crop management with multifunctional air-propelled abrasive grits. Weed Technol 28: 243-252. https://doi.org/10.1614/WT-D-13-00105.1

Wortman SE (2015) Air-propelled abrasive grits reduce weed abundance and increase yields in organic vegetable production. Crop Prot 77: 157-162. https://doi.org/10.1016/j.cropro.2015.08.001

Yuen KK (1974) The two-sample trimmed t for unequal population variances. Biometrika 61:165-170. https://doi.org/10.2307/2334299 